\title{
El pantà de Flix: Anàlisi i resolució d’un problema de contaminació forta
}

Joan 0. Grimalt (joan.grimalt@idaea.csic.es) Institut de Diagnosi Ambiental i Estudis de l'Aigua (IDAEA). Consell Superior d'Investigacions Científiques (CSIC).

En aquest article es realitza una perspectiva sobre el problema actual de contaminació greu de l'embassament de Flix (Ribera d'Ebre), generat pels abocaments massius dels residus de l'activitat d'una planta clor-àlcali al riu Ebre. La contaminació de l'embassament és a dos nivells: contaminació química (principalment metalls pesants $i$ compostos organoclorats) i contaminació radioactiva (radionúclids derivats de de l'238U). A l'article es detallen les causes i es presenten les mesures de descontaminació dutes a terme, les seves conseqüències i l'estat actual dels nivells de contaminació. Aquesta situació sense precedents tant en el context català i espanyol, com en el context europeu, afecta a un dels rius amb major importància per al territori. L'article finalitza amb algunes propostes de treball per a la solució definitiva del problema.

Paraules clau: Residus, contaminació forta, Ebre, Flix.

This paper presents a perspective of the current problem of severe contamination of the reservoir of Flix (Ribera d'Ebre), generated by massive discharges of waste from the activity of a Chloralkali plant on the river Ebro. The contamination of the reservoir is at two levels: chemical (mainly heavy metals and organochlorinated) and radioactive (derived radionuclides in the 238U). The article details the causes and the decontamination measures carried out, exposes its consequences and describes the current levels of contamination. This problem of contamination is of unprecedent gravity for the Catalan, the Spanish and the European context, and affects one of the most important rivers of the territory. The article ends with some future prospects as possible ways of solving the problem.

Keywords: XXXXXXXX

\section{INTRODUCCIÓ}

La contaminació és un problema derivat del desenvolupament humà. Som molts i utilitzem molts de recursos. Això ha generat que la petja humana sobre els ecosistemes sigui important. Els ecosistemes garanteixen la nostra qualitat de vida. Nosaltres utilitzem el medi ambient per acumular-hi les nostres deixalles. En reciclar ho fem d'una manera més racional $\mathrm{i}$ l'impacte és menor però així $\mathrm{i}$ tot hi ha un impacte. Afortunadament, els processos naturals ens retornen un aire net i una aigua neta (sempre que no els alterem massa). En aquest article no parlarem de la contaminació basal sinó de casos de contaminació forta per activitats humanes molt intensives sobre els ecosistemes.
Com a exemple agafarem el cas d'una planta clor-àlcali situada a la vora de l'embassament de Flix, en el riu Ebre, a uns $100 \mathrm{~km}$ riu amunt de la desembocadura.

\section{DEFINICIÓ DEL PROBLEMA}

Que hem de fer quan hi ha un problema de contaminació forta? La resposta és òbvia: arreglar-lo. Tothom hi està d'acord però entre el dit i el fet hi ha molts de camins $\mathrm{i}$ aquests poden esser tècnicament llargs i complicats, i tenir un cost econòmic. Però deixem els plantejament teòrics $i$ anem a la pràctica. 
A Flix hi ha una planta clor-àlcali que fa l'electròlisi de la sal dissolta en aigua (Figura 1). Usualment, aquestes instal-lacions tenen elèctrodes de grafit (ànode) i mercuri (càtode). Els productes generats en el procés són clor $\left(\mathrm{Cl}_{2}\right)$ i una amalgama de mercuri $(\mathrm{Hg})$ i sodi $(\mathrm{Na})$. Després aquesta amalgama reacciona amb aigua i produeix hidrogen $\left(\mathrm{H}_{2}\right)$ i sosa $(\mathrm{NaOH})$. Els productes que es poden comercialitzar en primer lloc són, per tant, clor, sosa i hidrogen.

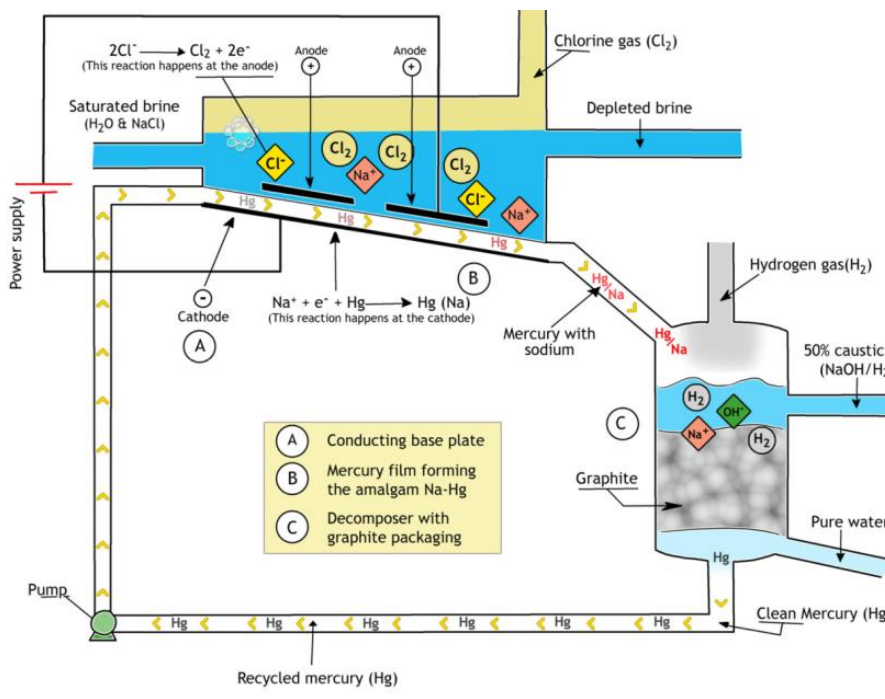

Figura 1. Esquema de funcionament d'una planta clor-àlcali.

El clor es pot utilitzar per fabricar altres compostos que tinguin més valor comercial. Per exemple DDT (entre 1945 i 1971), policlorobifenils (PCBs; 1959-1987), hexaclorociclohexans $\left(\mathrm{Cl}_{6} \mathrm{C}_{6} \mathrm{H}_{12}\right)$, tetraclorometà $\left(\mathrm{Cl}_{4} \mathrm{C} ; 1947-1979\right)$ i/o clorobenzens $\left(\mathrm{Cl}_{2} \mathrm{C}_{6} \mathrm{H}_{4}, \mathrm{Cl}_{3} \mathrm{C}_{6} \mathrm{H}_{3} ; 1947-1980\right)$. La fàbrica produí aquests compostos quan la legislació ho permetia. Aquesta és l'única fàbrica de l'Estat Espanyol que produí PCBs i fou la productora major de DDT.

Més recentment es fabricaren dissolvents organoclorats com el percloroetilè $\left(\mathrm{Cl}_{2} \mathrm{C}=\mathrm{CCl}_{2} ; 1972\right.$ actualitat), cloroform $\left(\mathrm{Cl}_{3} \mathrm{CH}, 1990\right.$-actualitat), dicloroetilè $\left(\mathrm{Cl}_{2} \mathrm{C}=\mathrm{CH}_{2}\right)$, tricloroetilè $\left(\mathrm{Cl}_{2} \mathrm{C}=\mathrm{CHCl}\right.$; 1963$1990)$, diclorometà $\left(\mathrm{Cl}_{2} \mathrm{CH}_{2} ; 1990\right.$-actualitat) i altres. A més d'aquests productes també es poden formar alguns compostos no desitjats, per exemple hexaclorobenze $\left(\mathrm{Cl}_{6} \mathrm{C}_{6}\right)$, pentaclorobenze $\left(\mathrm{Cl}_{5} \mathrm{C}_{6} \mathrm{H}\right)$, policloroestirens i altres.

La síntesi de compostos organoclorats a partir de clor suposa la generació d'àcid clorhídric $(\mathrm{HCl})$ com a subproducte. Cap al 1972 es decidí utilitzar aquest àcid per a fabricar fosfat bicàlcic $\left(\mathrm{CaHPO}_{4}\right)$ a partir de la fosforita (fosfat tricàlcic, $\mathrm{Ca}_{3}\left(\mathrm{PO}_{4}\right)_{2}$ ) que es portava del Marroc o de l'antic Sàhara espanyol.

Aquesta activitat anà combinada amb la construcció d'un embassament a l'estrada del meandre de Flix (Figura 2). Aquest embassament estava combinat amb dos túnels que travessaven la part estreta del meandre per sota. Un dels túnels estava fet per a passar barques i l'altra per a aprofitar el salt d'aigua que hi ha entre les dues parts del meandre. Així, en travessar l'aigua per sota hi ha un salt que mou una turbina i es genera energia hidroelèctrica. La paret de l'embassament estava dedicada a retenir l'aigua del riu i assegurar un cabal a través de la turbina. Aquest embassament no és un dipòsit d'aigua perquè està fet en una zona que no té capacitat d'emmagatzematge. Malgrat això, la presència de l'embassament fa que l'aigua del riu Ebre quedi retinguda i que s'hi puguin acumular els residus abocats per la planta clor-àlcali. Aquest embassament es construí en un període en què també es construïren els embassaments de Ribarroja i de Mequinença, el primer per emmagatzemar less aigües de l'Ebre i del Segre i el segon per recollir les aigües de l'Ebre i del Cinca. Aquests dos embassaments aigües amunt retenen els contaminants abocats als cursos d'aigua i per tant les aigües alliberades després de l'embassament de Ribarroja tenen concentracions de contaminants molt baixes.

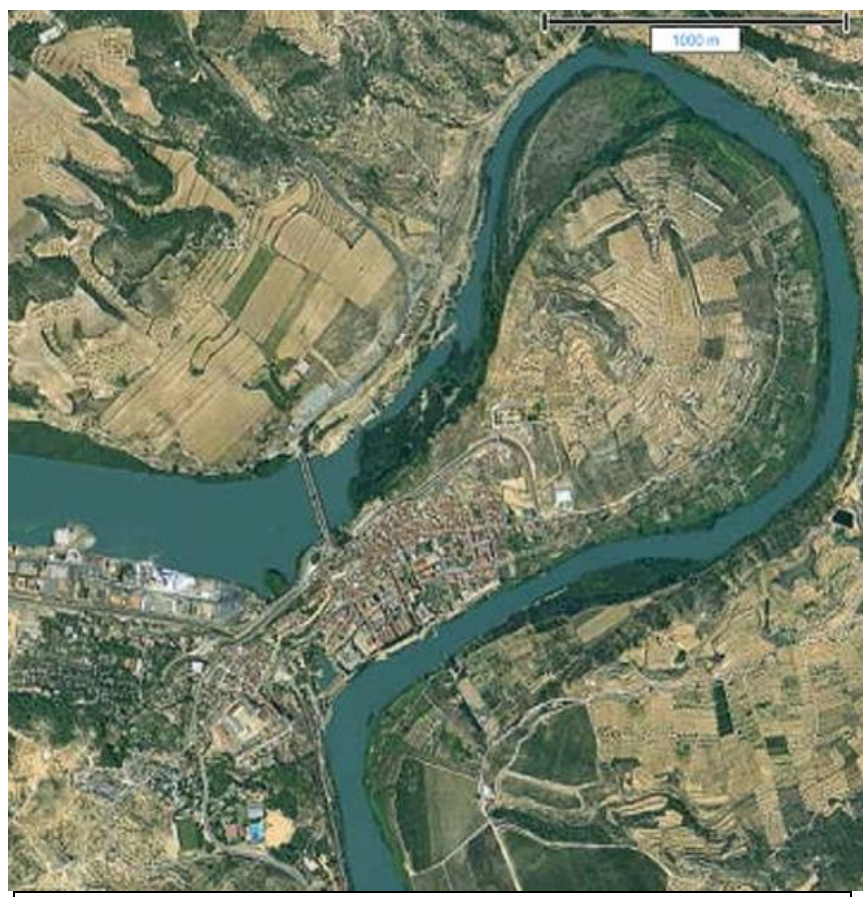

Figura 2. Meandre de Flix, on es mostra la paret de l'embassament i els canals subterranis 
L'ús del mineral de la fosforita per a obtenir fosfat bicàlcic comportà que el residu d'aquest mineral s'aboqués a l'embassament (Palanques et al., 2014). Aquesta activitat donà lloc a la creació d'un delta a la vora de la planta clor-àlcali essencialment format per aquests residus (unes 350.000 tones). Aquest delta arribà a ocupar un $60 \%$ de la secció de pas de l'aigua del riu (Figura 3A). Com passa en altres residus de fosforita, els residus abocats contenien urani $\left({ }^{238} \mathrm{U}\right)$ i tots els radionúclids de la cadena de descomposició d'aquest element, essencialment: tori $\left({ }^{234} \mathrm{Th}\right),{ }^{234} \mathrm{U},{ }^{230} \mathrm{Th}$, radi $\left({ }^{226} \mathrm{Ra}\right)$, poloni (218Po), plom $\left({ }^{214} \mathrm{~Pb}\right)$, Bismut $\left({ }^{214} \mathrm{Bi}\right),{ }^{214} \mathrm{Po},{ }^{210} \mathrm{~Pb}$, ${ }^{210} \mathrm{Bi}$ i ${ }^{210} \mathrm{Po}$ (Grimalt et al., 2003). La presència d'aquests radionúclids proporcionava un cert nivell de radioactivitat als residus, en l'ordre dels 70$12000 \mathrm{~Bq} / \mathrm{kg}$ per cada element. Des d'un punt de vista legal, la radioactivitat d'aquests tipus de residus (extrets d'una mina) es considera natural i per tant no hi ha una norma general de tractament. Malgrat això, les activitats màximes dels radionúclids mesurats, $3.5 \cdot 10^{3} \mathrm{~Bq} \cdot \mathrm{kg}^{-1}$ de ${ }^{210} \mathrm{~Pb}, 9.4 \cdot 10^{3}$ $\mathrm{Bq} \cdot \mathrm{kg}^{-1}$ de ${ }^{226} \mathrm{Ra}$ i $1.2 \cdot 10^{4} \mathrm{~Bq} \cdot \mathrm{kg}^{-1}$ de ${ }^{238} \mathrm{U}$ són més altes que les dels Basic Standards de l'Agència Internacional de l'Energia Atòmica (IAEA) del 1996 (96/29/Euratom i el Real Decreto 1836/1999) que marquen com a activitats màximes exemptes de declaració $10^{4} \mathrm{~Bq} \cdot \mathrm{kg}^{-1}$ d'activitat total o bé $10^{4}$ $\mathrm{Bq} \cdot \mathrm{kg}^{-1}$ per al ${ }^{210} \mathrm{~Pb} \mathrm{i}^{226} \mathrm{Ra}$ o $10^{3} \mathrm{~Bq} \cdot \mathrm{kg}^{-1}$ per al ${ }^{238} \mathrm{U}$.

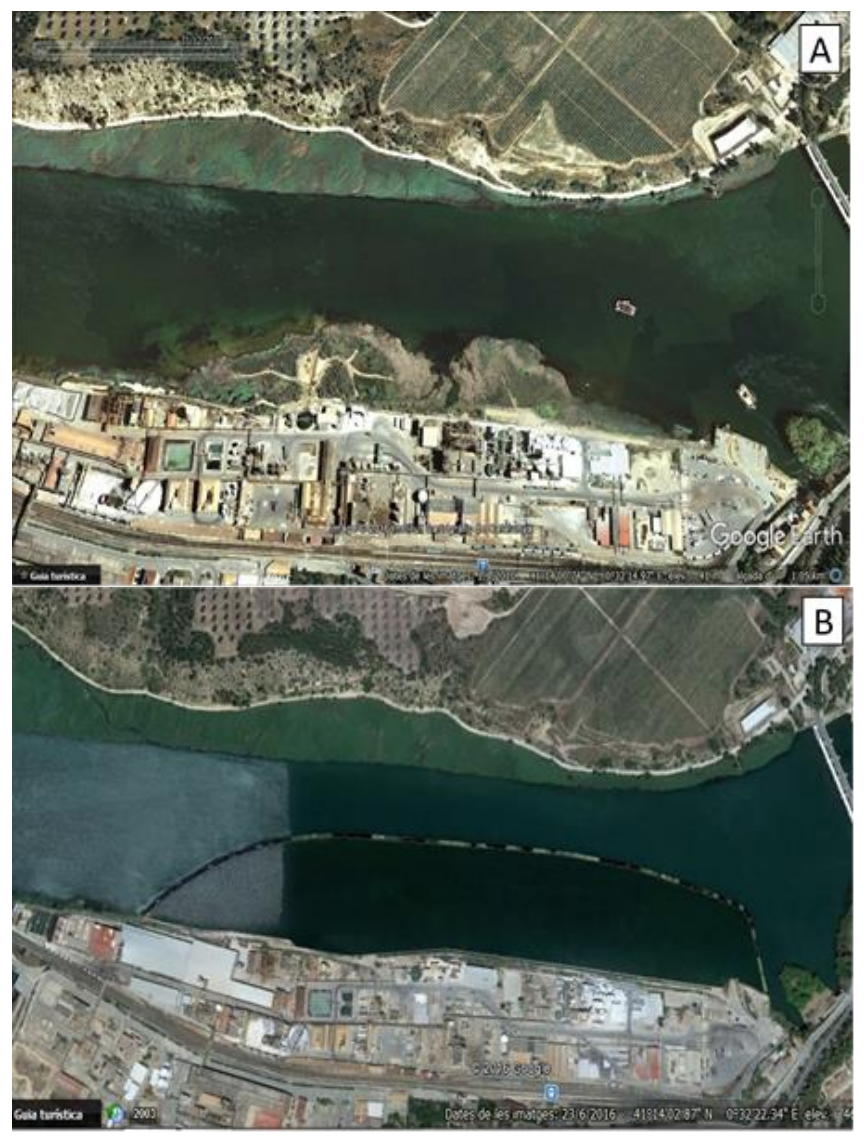

Figura 3. Fotografies del Google Earth que mostren l'embassament de Flix en dates 1/4/2010 (A) i 23/6/2016 (B).

A més d'això, aquests residus tenien mercuri, cadmi $(\mathrm{Cd})$, crom $(\mathrm{Cr})$, níquel $(\mathrm{Ni})$, policloronaftalens, policloroestirens, DDT, policlorobifenils, policloroestirens, hexaclorobenzè, pentaclorobenzè, clorobenzens, percloroetilè i hexaclorociclohexans entre altres.

A nivell de quantitats totals, en els residus abocats hi havia 4-7 tones d'hexaclorobenzè, 8-16 tones de policlorobifenils, 10-18 tones de mercuri, 4276 tones de crom, 13-24 tones de níquel, $22-40$ tones de zinc i 0.5-0.8 tones de cadmi.

Riu avall de l'embassament de Flix les concentracions de radionúclids trobades en els sediments estaven dins de la normalitat. En canvi, el mercuri i el cadmi mostraven una contaminació molt important en tot el tram fins a la desembocadura. L'hexaclorobenzè, els policlorobifenils i el 4,4'-DDT també es trobaven en concentracions importants. En el mateix ordre o més que les trobades a llocs de contaminació alta (Bosch et al., 2009). Els organismes, peixos, crancs, mostraven concentracions de mercuri importants, sovint per sobre dels nivells indicats per la Unió Europea com a aptes pel consum humà, des de l'embassament fins a la boca, tot incloent els agafats als canals de reg del delta (Faria et al., 2009). A nivell de compostos organoclorats també s'observaven concentracions altes (Huertas et al., 2016).

En resum, el problema de la contaminació química (metalls pesants, compostos organoclorats) i radioactiva (radionúclids derivats de l'238U), juntament amb la importància del riu Ebre $\left(600 \mathrm{~m}^{3} / \mathrm{s}\right)$, la situació de la bossa de residus (360000 tones situades a $95 \mathrm{~km}$ aigües amunt de la desembocadura) i la importància econòmica i social del territori que es troba aigües avall feien del cas de l'embassament de Flix un problema únic en el context català, espanyol i europeu. Aquesta situació demanava una acció ràpida i eficient davant del risc ambiental evident que representava. Cal tenir present que encara que globalment aquesta massa de residus tenia una certa estabilitat per l'embassament passen totes les aigües abocades pel riu Ebre, el Cinca i el Segre. No es pot descartar, per tant, una crescuda que arrossegués una part substancial dels residus acumulats a l'embassament de Flix. 


\section{COM ES TROBÀ EL PROBLEMA?}

La figura 3A mostra com era l'embassament de Flix abans del 2010. Qualsevol podia veure la massa de residus que hi havia a l'embassament. No hi havia cap misteri. Molta gent sabia que aquests materials venien de residus abocats per la fàbrica. Aleshores, com és que no s'actuà abans?

Doncs precisament perquè encara que es veia no se sabia què hi havia ni si el que hi havia era tòxic i fins a quin grau. La descripció de la secció anterior d'aquest article correspon a les troballes resultants d'uns 10 anys d'estudis. Cal dir que, irònicament, a mesura que s'anava descrivint la composició i quantitat de materials abocats a l'embassament diversos portantveus de l'organisme espanyol responsable de la conca van deixar caure que "tot això ja era conegut i se sabia". No calen comentaris.

L'inici de l'estudi comença a rel d'una entrevista que l'autor d'aquest treball va tenir amb el primer Conseller de Medi Ambient de la Generalitat de Catalunya, el Sr. Albert Vilalta. Amb motiu d'una entrevista per un altre tema, i tenint en compte alguns resultats de la meva tesi doctoral feta sota la direcció del Prof. Joan Albaigés, on es mostrava que en el delta de l'Ebre hi havia residus de DDTs i PCBs, vaig esmentar al Conseller que un tema ambiental molt important a Catalunya eren els residus abocats a aquest l'embassament. Dies després, em trucaven de la Junta de Residus de la Generalitat de Catalunya perquè posés en marxa un projecte d'estudi de la contaminació d'aquest embassament. En una reunió presidida pel Conseller $i$ on hi havia representants de la Junta de Residus (futura Agència de Residus de Catalunya) i de la Junta de Sanejament (futura Agència Catalana de l'Aigua) es decidí fer un estudi. Per tal de minimitzar els costos es decidí fer-lo en dues etapes, una primera d'estudi dels residus superficials i una segona d'estudi de la massa de residus en profunditat (perfils verticals) en el cas que les concentracions superficials fossin altes. S'establí el finançament per la primera etapa. Els resultats mostraren unes concentracions molt altes dels compostos organoclorats esmentats anteriorment, fonamentalment hexaclorobenzè, PCBs i DDTs, a més de mercuri i altres metalls.

A l'hora de començar la segona etapa, el context institucional havia variat una mica. El Sr. Vilalta ja no era conseller i se'ns indicà que aquesta segona etapa s'havia de realitzar subvencionada per l'empresa responsable dels abocaments. Hi hagué un període llarg de converses entre diferents organismes catalans i espanyols que al cap de dos anys no acabaren en res concret. Més tard la Generalitat de Catalunya, mitjançant la Comissió Interdepartamental de Recerca i Tecnologia (CIRIT; l'antecedent de l'AGAUR), convocà tres projectes de recerca sobre temes ambientals importants. El meu grup de treball hi concursà amb un projecte per estudiar la contaminació per compostos organoclorats i mercuri a tots els rius de Catalunya. Aquest projecte es finançà i permeté continuar l'estudi.

Vam traslladar un vaixell de fons molt pla des del port de Barcelona a l'embassament de Flix. Això fou un esforç tècnic molt important liderat pel meu company del CSIC, Albert Palanques, actual director de l'Institut de Ciències del Mar. Amb aquest vaixell i un sistema de vibrocores poguérem mostrejar tota la columna de residus que hi havia. El mostratge fou molt accidentat perquè el primer dia que posàrem el vaixell al riu es féu una buidada de l'aigua retinguda a l'embassament de Ribarroja. Va ésser una sorpresa majúscula, i un risc molt alt per la seguretat de la tripulació del vaixell. Des del vaixell s'observà un increment del flux d'aigua del riu molt alt que l'empenyia cap a la paret de l'embassament de Flix, amb el risc d'una caiguda d'uns 30 metres. Aquest risc es podia controlar amb el motor del vaixell però com a conseqüència de l'augment del cabal també davallaven pel curs del riu un munt de troncs i branques d'arbres amb el risc d'aturar l'hèlix del vaixell. $\mathrm{Ni}$ a la Junta de Sanejament ni a la Confederación Hidrográfica del Ebro sabien res d'un buidatge de l'embassament de Ribarroja en aquelles dates. Després de diverses trucades finalment va ésser personal de la Junta de Sanejament que ens avisà que marxéssim d'allà immediatament perquè venia una punta d'aigua molt forta. Vam haver d'atracar el vaixell a les instal-lacions de Ribarroja i vam haver de mantenir-lo allà aturat quatre dies (només el teníem llogat per una setmana). Finalment, amb el temps que ens quedà disponible vam poder mostrejar 5 testimonis. Mai no em sabut per què es va buidar de forma imprevista el pantà de Ribarroja en aquelles dates. Les barques del seu club nàutic quedaren penjant de les cordes.

L'estudi dels sediments en profunditat ens mostrà una nova dimensió del problema. Teníem previst datar els residus per la tècnica del ${ }^{210} \mathrm{~Pb}$ que mesura les diferències d'activitat d'aquest radionúclid com a conseqüència de l'emissió de radó $\left({ }^{222} \mathrm{Rn}\right)$ provinent de certes roques, fonamentalment granits. Les dades mostraren que no es podia fer aquesta datació perquè els nivells de ${ }^{210} \mathrm{~Pb}$ eren molt alts. Després de diverses consideracions finalment els membres de l'equip expert en radionúclids, liderat pel Joan Albert Sanchez-Cabeza, de I'Institut de Ciència i Tecnologia Ambiental (IRTA) 
de la Universitat Autònoma de Barcelona, trobaren que aquests nivells tan alts d'aquest radionúclid provenien de ${ }^{238} \mathrm{U}$ present en els materials de la fosforita. Per tant, no era possible datar el paquet de residus. La troballa emperò aportava una nova dimensió al problema en haver-hi radionúclids.

Acabat l'estudi dels materials presents a l'embassament un altre tema objecte d'interès fou quin era l'impacte riu avall d'aquests residus. Aquest tema s'abordà mitjançant un finançament del Ministeri de Medi Ambient del Govern d'Espanya i l'Agència Catalana de l'Aigua. En la promoció d'aquest finançament i l'estudi de la resolució del problema intervingué el Conseller de Medi Ambient de la Generalitat de Catalunya, Salvador Milà. Els resultats s'han descrit a la secció anterior. Aquest i el seu successor, Francesc Baltasar, també donaren suport a la comissió d'estudi que arribà a definir la solució per a l'extracció dels residus que es descriu a continuació.

\section{COM S’ARREGLÀ EL PROBLEMA?}

Un cop identificat el problema es decidí fer una comissió on estaven representats els organismes responsables de la gestió del riu (Confederación Hidrogràfica del Ebro, Agència Catalana de l'Aigua), membres de la comunitat científica (Universitats de Barcelona, Autònoma de Barcelona, Politècnica de Catalunya, Girona, Rovira i Virgili, CSIC), Associacions de Regants, Ajuntament de Flix, Grup de Natura Freixe i altres. La comissió estava presidida per la Confederación Hidrogràfica del Ebro que és l'organisme amb més competències sobre el riu. El treball conjunt d'aquesta comissió va concloure que la retirada dels residus del riu era necessària. Això comportava la seva depuració i emmagatzematge en un abocador controlat.

Amb aquest objectiu es féu un projecte que comprenia:

a) Construcció d'un abocador (zona del Racó de la Pubilla)

b) Construcció d'un mur de protecció de les instal-lacions de l'empresa.

c) Tancament dels residus presents a l'embassament amb una paret doble de palplanxes

d) Retirada dels residus, filtració i depuració.

e) Cementació si el contingut dels residus extrets tenia molt de $\mathrm{Hg}$.

f) Evaporació dels compostos organoclorats dels residus extrets si la concentració era alta.

g) Abocament dels residus tractats a l'abocador
La paret de palplanxes per aïllar la massa de residus de l'erosió de les aigües del riu era necessària perquè sinó en treure els residus hi hauria un efecte d'arrossegament riu avall de part d'aquests. La planta de tractament químic tenia un sistema de filtració premsa per a disminuir la quantitat d'aigua present en els residus (l'aigua filtrada es tractava en una depuradora $i$ es tornava al recinte tancat) $i$ després sistemes de cimentació si el residu tenia molt de mercuri i evaporació si el residu tenia molts de compostos organoclorats. L'abocador dels residus tractats proporcionava un destí final als residus després de tractar-los. Aquest abocador era per a residus d'activitat intermèdia, no residus especials. Per això calia depurar-los si la concentració de mercuri o de compostos organoclorats era alta.

Aquest projecte ja s'ha aplicat. Va patir diverses demores mai adequadament explicades però finalment es va posar en marxa. El projecte es pressupostà en uns 180 milions d'euros i va comptar amb un finançament de la Unió Europea d'un $70 \%$ del cost. Tot el finançament era d'origen públic. La reparació d'aquesta contaminació no suposava una càrrega econòmica per a l'empresa.

A la Figura 3B es mostra com ha quedat l'embassament després de la retirada dels residus. Encara s'hi troba la paret de palplanxes. La diferència entre la situació de l'embassament abans i després és espectacular. Actualment, s'ha fet un estudi addicional per comprovar l'eficiència de la retirada dels residus sòlids. També cal establir el procediment de depuració de les aigües retingudes en la doble paret de palplanxes. A l'hora d'escriure aquest article hi ha un grau d'incertesa de com s'acabaran de resoldre aquests temes. Òbviament, un cop resolts aquests dos aspectes, caldrà retirar la paret de palplanxes. Aquesta paret ha aïllat perfectament les aigües interiors, contaminades amb els residus, de les exteriors del riu. S'ha protegit contra la corrosió mitjançant l'aplicació d'un voltatge catòdic de $20 \mathrm{~V}$.

Aquest projecte és l'únic finançat per la Unió Europea que ha comportat una feina tan intensiva d'eliminació de residus industrials a Catalunya $\mathrm{i}$ l'Estat Espanyol. A ben pocs llocs d'Europa s'han fet actuacions semblants. Això mostra la importància del cas tractat i l'èxit aconseguit per tots els organismes implicats a l'hora de trobar una solució (tècnica i econòmica).

\section{Quan creus que ja s'acaba torna a començar (Raimon, 1969)}

La Unió Europea fa anys que tenia previst prohibir l'ús de mercuri en les plantes clor-àlcali. Des- 
prés de diferents retards aquesta normativa s'implementa el 2017. Les instal-lacions d'aquest tipus que no canviïn la tecnologia (a elèctrodes de membrana) han de tancar. Aquest és el cas de la planta de Flix, que l'empresa ERCROS ha decidit aturar. Davant la marxa d'aquesta empresa queda un altre problema, quin són els residus acumulats en el sòl industrial i com s'ha de tractar aquest tema?

Dades inicials provinents d'informes dels que disposa l'Agència de Residus de Catalunya mostren que hi ha una contaminació molt alta per diversos dissolvents organoclorats enterrats en els sòls de l'empresa. Aquests residus estan contaminant les aigües subterrànies i una part van al riu Ebre. Cal un estudi integral d'aquest problema i de la situació general dels residus abocats per l'empresa a la zona per definir quina és la millor estratègia d'actuació davant problema nou plantejat.

\section{QUĖ S'HA DE FER PER RESOLDRE AQUEST TIPUS DE PROBLEMES?}

Com s'ha dit al principi, la resolució de problemes ambientals greus barrejats amb interessos econòmics i socials importants no és senzilla. És imprescindible un assessorament científic de qualitat. Això demana als investigadors interessats un esforç per estudiar el problema i abordar aquest amb objectivitat, deixant de banda interessos colaterals. És necessari conèixer l'abast qualitatiu i quantitatiu del problema. Aquesta feina usualment va acompanyada de la feina típica dels científics com és publicar els resultats de la seva recerca en revistes especialitzades que passen per revisió externa.

També cal ésser molt conscient de les repercussions d'aquest tipus de treball en els diferents agents socials, treballadors de l'empresa, veïns d'habitatges propers al poble, etc. Addicionalment es pot donar el cas que calgui cercar finançament per dur a terme les activitats de recerca que cal realitzar.

Una tasca que sovint es planteja és comunicar els resultats trobats. Aquesta informació s'ha de donar en primer lloc a les persones responsables que poden contribuir a solucionar el problema. Cal, per tant, un plantejament institucional i de lleialtat amb els interlocutors. Aquest paper però no pot ser de subordinació. Cal explicar el problema i tots els aspectes del problema.

Quan és el moment de parlar amb els mitjans de comunicació convé fer-ho en col-laboració i/o coordinació amb les institucions que poden solucionar els problemes. Però quan es parla cal dir la veritat, tota la veritat i res més que la veritat.

El paper de l'investigador en temes ambientals és molt important per resoldre aquest tipus de problemes. S'ha d'estar preparat per esmolar els coneixements i abordar el problema amb objectivitat. També s'ha d'estar preparat per saber que a vegades tractar aquests problemes de forma independent no és la millor manera de fer amics. A la frase de l'Albert Einstein que deia que "els que tenen el privilegi de saber tenen el deure d'actuar" es pot afegir que "no hi ha més beneit que el que no vol saber".

\section{REFERÈNCIES}

BOSCH, C., A. OLIVARES, M. FARIA, J.M. NAVAS, I. DEL OLMO, J.O. GRIMALT, B. PIÑA, C. BARATA (2009). Identification of water soluble and particle bound compounds causing sublethal toxic effects. A field study on sediments affected by a chlor-alkali industry. Aquat Toxicol. $94,16-27$

FARIA, M., D. HUERTAS, D.X. SOTO, J.O. GRIMALT, J. CATALAN, M.C. RIVA, C. BARATA (2010). Contaminant accumulation and multibiomarker responses in field collected zebra mussels (Dreissena polymorpha) and crayfish (Procambarus clarkii), to evaluate toxicological effects of industrial hazardous dumps in the Ebro river (NE Spain). Chemosphere 78, 232240

GRIMALT, J.O., J.A. SANCHEZ-CABEZA, A. PALANQUES, J. CATALAN (2003). Estudi de la dinàmica dels compostos organoclorats persistents $i$ altres contaminants en els sistemes aquàtics continentals. Consell Superior d’Investigacions Científiques. 254 p.

D. HUERTAS, J.O. GRIMALT, J. BENITO, L. BENEJAM, E. GARCÍA-BERTHOU (2016). Organochlorine compounds in European catfish (Silurus glanis) living in river areas under the influence of a chlor-alkali plant (Ebro River basin). Sci. total Environ. 540, 221-230

PALANQUES, A., J.O. GRIMALT, M. BELZUNCES, F. ESTRADA, P. PUIG AND J. GUILLÉN (2014). Massive accumulation of highly polluted sedimentary deposits by river damming. Sci. total Environ. 497-498, 369-381 